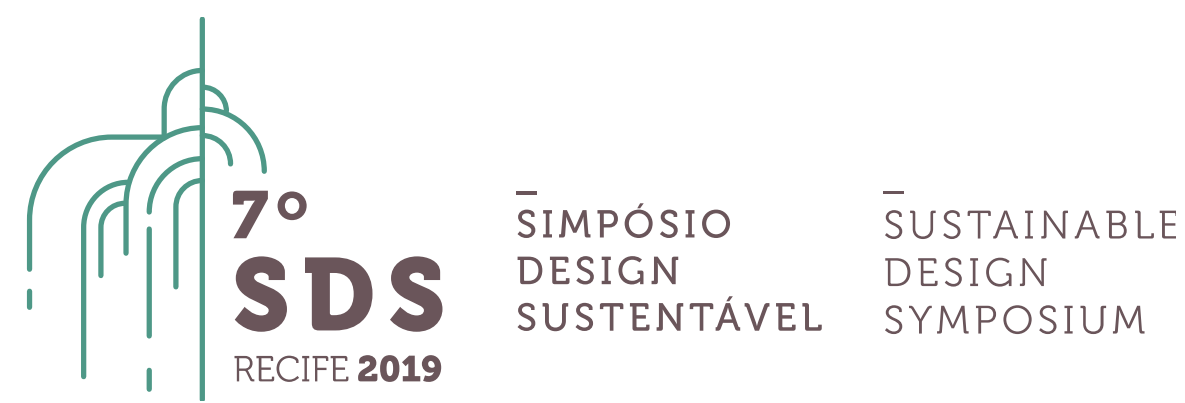

\title{
EdESIGN tool: platform for integration of knowledge in Design and Sustainability
}

\footnotetext{
Vanessa Gomes Santana ${ }^{1 a}$, Maria Thatiane Ramalho ${ }^{2}$, Adriana Paula Oliveira Santos ${ }^{3}$ and Áurea Luiza Rapôso ${ }^{4}$

${ }^{1}$ Graduate Student, Federal Institute of Alagoas, Research Group in Design and Interdisciplinary Studies (GEID) and Multidisciplinary Group of Research in Education (GEMPE), vanessa.gomes24@hotmail.com

${ }^{2}$ Graduate Student, Federal Institute of Alagoas, Research Group in Design and Interdisciplinary Studies (GEID), thatyramalho@hotmail.com

${ }^{3}$ Doctor Degree in Education, Federal Institute of Alagoas, Multidisciplinary Group of Research in Education (GEMPE), apquixabeira@gmail.com

${ }^{4}$ Doctor Degree in Industrial Engineering, Federal Institute of Alagoas, Research Group in Design and Interdisciplinary Studies (GEID), alqrsraposo@gmail.com

${ }^{a}$ Av. do Ferroviário, 530, Centro, Maceió-AL, 57020-600
}

\begin{abstract}
This article aimed to present of the EdESIGN tool as a platform for integration of knowledge in Design and Sustainability, based on two databases developed in research projects on the knowledge and skills mobilized in the teaching-learning process by students and lecturers of the technological course in Interior Design (database 1) and on the knowledge and skills mobilized in social and environmental actions of furniture companies of micro and small size (database 2). The main motivation of the project was associated to the demands of socio-environmental and innovative solutions for the practice of Sustainability within the scope of the work of interior designers and the development of products, processes and services of local furniture companies, intermediated in interior projects. As applied research and with qualitative approach, the methodological procedures used were the bibliographic research and the case study. The selected methodological instruments were online questionnaire for the construction of the profiles of the target public; brainwriting design tool and project briefing for the development of website format. As a product and main result of the research, the EdESIGN tool was created as a website, constituting a platform for integrating of knowledge in Design and Sustainability, a source of reference and consultation for students and teachers and local companies, composed of by 4 modules: Academic module, Professional module, Business module and Tips module.
\end{abstract}

Keywords. Sustainability; Design; Platform for integration; Knowledge; Design tool. 


\section{Introdução}

Os projetos, produtos, serviços, processos e/ou sistemas, criados por designers e empresas locais - no âmbito do design de interiores e design de móveis e utensílios - vêm solicitando maior atenção e atendimento às exigências socioambientais e legais quanto à prevenção e/ou redução de impactos para o meio ambiente, para a sociedade e para a Sustentabilidade global. A regulamentação ambiental incentiva à adoção de tecnologias e processos limpos que reduzam emissões, resíduos, consumo de recursos e uso de materiais prejudiciais. Ao considerar o impacto socioambiental de projeto, produto, serviço, processo e/ou sistema, os requisitos de design devem se associar às boas práticas para a Sustentabilidade (THOMPSON, 2015; PLATCHECK, 2012).

No cenário brasileiro, regional e/ou local, as boas práticas para a Sustentabilidade destacam-se de forma evolutiva, no que concerne à legislação ambiental, com as Políticas Nacionais de Meio Ambiente (Lei no 6.938/1981), de Educação Ambiental (Lei no 9.795/1999) e de Resíduos Sólidos (Lei no 12.305/2010, PNRS), além de resoluções, normas técnicas e outras diretrizes (OLIVEIRA SANTOS; RAPÔSO; FARTES, 2011).

No que lhe concerne, pela Lei no 13.369 de dezembro de 2016 (BRASIL, 2019, p. 1, online, grifos nossos), o designer de interiores é o "[...] profissional que planeja e projeta espaços internos, visando ao conforto, à estética, à saúde e à segurança dos usuários, [...]" (Art. 2º); e, para isto, deve "[...] IV - compatibilizar os seus projetos com as exigências legais e regulamentares relacionadas a [sic] segurança contra incêndio, saúde e meio ambiente; [...]", além de zelar "I pela conduta ética; [...]; III - pela sustentabilidade; IV - pela responsabilidade social; V - pela segurança dos usuários, evitando a exposição desses a riscos e potenciais danos" (Art. 5ㅇ). As habilidades e competências em negrito conectam o designer de interiores como agente das boas práticas para a Sustentabilidade junto aos setores produtivos em que atua.

Isto posto, neste artigo, apresenta-se proposta de ferramenta que consiste em oferecer suporte para demandas de soluções socioambientais e inovadoras para a prática da Sustentabilidade no âmbito do Design, a partir da integração de saberes e competências em Design e Sustentabilidade, reunidos em dois bancos de dados, resultantes de Pesquisas de Iniciação Científica (PIBIC), desenvolvidas no período de 2016-2017 (Projetos A e B), como ilustra a Figura 1.

Figura 1 - Proposta da Ferramenta EdESIGN

\begin{tabular}{|c|c|c|}
\hline \multicolumn{3}{|c|}{ Ferramenta EdESIGN } \\
\hline \multirow[t]{2}{*}{$\begin{array}{l}\text { Plataforma de integração de } \\
\text { saberes em Design e } \\
\text { Sustentabilidade }\end{array}$} & $\begin{array}{c}\text { PROJETO A } \\
\text { BANCO DE DADOS } 1 \\
\text { Saberes e competências para } \\
\text { Formação do Designer de } \\
\text { Interiores }\end{array}$ & $\begin{array}{c}\text { PROJETO B } \\
\text { BANCO DE DADOS } 2 \\
\text { Saberes e competências para Práticas } \\
\text { Socioambientais aplicadas ao Design de } \\
\text { Móveis }\end{array}$ \\
\hline & SABER-SER & SABER-AGIR \\
\hline
\end{tabular}

Fonte: Projeto PIBIC 2017-2018 (GEID; GEMPE, 2017)

A Figura 1 sintetiza a proposta da ferramenta EdESIGN para integrar os bancos de dados 1 e 2, que buscou responder o seguinte problema: Como integrar saberes e competências em Design e Sustentabilidade em plataforma (website) que viabilize a interação entre designers de interiores $e$ empresas locais em contextos formativos (SABER-SER) e profissionais (SABER-AGIR) relacionados às boas práticas da Sustentabilidade? 
A ferramenta $E d E S I G N$ desenvolvida constitui-se em referência e fonte de consulta para discentes e docentes do Curso Superior de Tecnologia em Design de Interiores do Instituto Federal de Alagoas (Ifal) e de outras Instituições de Ensino Superior (IES), bem como para os atores de empresas locais, cujos projetos, produtos, serviços, processos e/ou sistemas estejam, direta e indiretamente, ligados aos setores produtivos vinculados ao Design de Interiores e ao design moveleiro, além de profissionais de Design, Arquitetura e Urbanismo, Engenharia e áreas afins.

Para melhor compreensão sobre os referenciais norteadores da plataforma, é relevante introduzir o conceito de saberes e competências. De acordo com Libâneo (2004, p. 77), "Saberes são conhecimentos teóricos e práticos requeridos para o exercício profissional, competências são as qualidades, capacidades, habilidades e atitudes relacionadas a esses conhecimentos teóricos e práticos e que permitem a um profissional exercer adequadamente sua profissão". Ou seja, para o exercício de qualquer profissão, todo profissional constrói e carrega consigo um repertório de conhecimentos teóricos e práticos, bem como precisa deter certas habilidades necessárias para a atuação profissional.

A construção desse repertório de conhecimentos teóricos e práticos, sob a óptica do Design, voltados para a Sustentabilidade, deve adotar visão sistêmica e integradora dos vários campos do conhecimento humano, que abrange tanto a inter-relação ambiente natural-artificial quanto à inter-relação ambiente-humano, como destaca Sampaio et al. (2018). Para os autores, ao tomar a Sustentabilidade como integradora de conhecimentos, busca-se superar as divisões típicas da especialização científica; e, assume-se a visão de interligação para que a compreensão, tanto dos problemas socioambientais quanto das soluções socioambientais inovadoras, esteja voltada à complexidade inerente aos contextos formativos, profissionais e produtivos, relativos à fabricação, ao consumo e ao descarte de bens e serviços.

Outro viés relevante para a pesquisa foi o papel que a Educação Ambiental exerce na formação de uma consciência e sensibilização ambiental coletiva. Segundo Oliveira Santos, Rapôso e Fartes (2011), a Educação Ambiental consiste em estratégia para difusão da informação ambiental, necessitando de aprimoramentos para que o fluxo e refluxo dessa informação atinjam a população, de modo a despertar e formar a preocupação individual e coletiva que oriente o desenvolvimento de consciência ambiental proativa e a construção de valores sociais, conhecimentos, habilidades, atitudes e competências, voltados para preservação e conservação do meio ambiente, e consequentemente, para saúde e qualidade da vida humana, bem como para a Sustentabilidade.

Acredita-se que o material a ser disponibilizado às comunidades acadêmica, profissional e empresarial, por meio da Ferramenta EdESIGN, contribuirá para ampliação de conhecimentos em relação à Sustentabilidade, auxiliando os interessados a incorporar, no dia-a-dia, ações relacionadas às boas práticas. O presente artigo aborda, especificamente, o processo de criação da plataforma e as estratégias utilizadas para revisão dos bancos de dados que foram a base de informações e conhecimentos produzidos por Pesquisa de Iniciação Científica - PIBIC (2017-2018). Nas seções de Método de Pesquisa e Resultados e Discussões, apresenta-se o caminho percorrido para alcançar os resultados obtidos e atingir os objetivos da plataforma.

\section{Método de Pesquisa}

A pesquisa caracterizou-se, quanto à natureza, como pesquisa aplicada; e, quanto à abordagem, como pesquisa qualitativa, por constituir sua base investigativa na análise dos bancos de dados 1 e 2 e por buscar a compreensão dos conceitos, saberes e competências relacionados à Sustentabilidade e ao Design, a partir dos contextos da formação tecnológica de designers de 
interiores do Ifal e dos contextos da produção moveleira local (COSTA; COSTA, 2014).

Os processos metodológicos selecionados para a pesquisa PIBIC (2017-2018) foram a pesquisa bibliográfica e o estudo de caso; este último, em virtude da criação de ferramenta enquanto produto digital (website). Com base em Costa e Costa (2014) o desenvolvimento da pesquisa teve duas etapas, como mostra a Figura 2.

Figura 2 - Etapas de desenvolvimento da Pesquisa

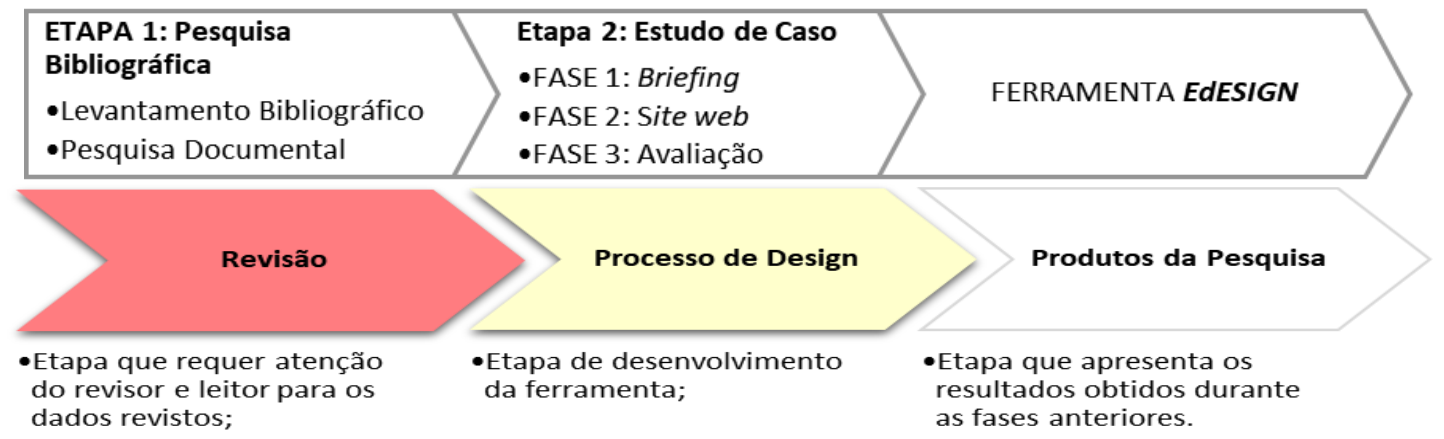

Fonte: Projeto PIBIC 2017-2018 (GEID; GEMPE, 2017)

A etapa 1 foi composta por Pesquisa Bibliográfica, com leituras e fichamentos para construção do aporte teórico, realizado por meio de levantamento bibliográfico em livros e artigos científicos e por pesquisa documental nos bancos de dados - revisão das pesquisas anteriores.

O processo de análise e síntese durante a revisão dos dados possibilitou a categorização e classificação das informações, bem como o desenvolvimento de ilustrações (figuras, quadros, gráficos e tabelas), dispostos em fichas técnicas para composição do fichário de pesquisa. $\mathrm{O}$ que demandou também a elaboração de sistema de cores - vermelho, amarelo e branco (cf. Fig. 2) para continuidade das fichas técnicas elaboradas nos projetos $A$ e $B$, visto que essa técnica de produção de fichários tem sido adotada pelos pesquisadores do Grupo de Design e Estudos Interdisciplinares (GEID) e do Grupo Multidisciplinar de Estudos e Pesquisas em Educação (GEMPE) em projetos de pesquisa e de extensão desde 2014.

Na etapa 2, o Estudo de Caso foi dividido em 3 fases. A Figura 3 representa a divisão das Fases 1, 2 e 3 do Estudo de Caso e apresenta os passos seguidos para atingir os objetivos relativos às Fases 1 e 2, concluídas em 2018.

Figura 3 - Fases de elaboração do site da Ferramenta EdESIGN (Etapa 2)

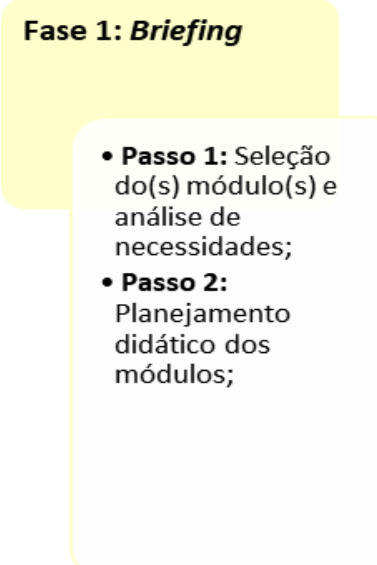

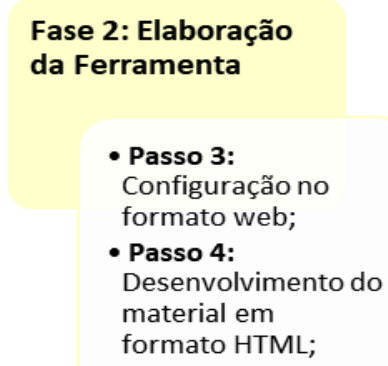

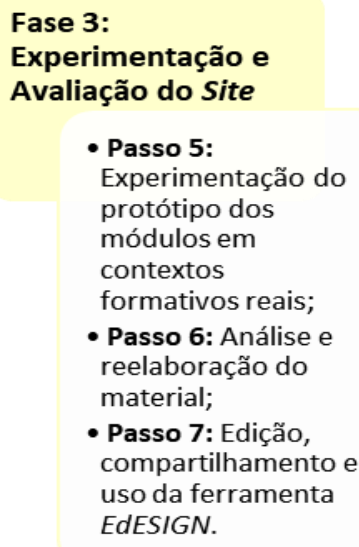

Fase 3: Experimentação e Avaliação do Site

- Passo 5: Experimentação do protótipo dos módulos em contextos formativos reais; - Passo 6: Análise e reelaboração do material;

- Passo 7: Edição, compartilhamento e uso da ferramenta EdESIGN. (1) 
Na Fase 1 foram realizadas as primeiras atividades de discussão sobre a ferramenta, que contribuíram para estruturação do site e seleção dos conteúdos dos módulos. Na Fase 2 a estrutura do website foi concebida, organizada e construída. A Fase 3 , destinada à experimentação e avaliação do website, ainda não foi executada, em função do tempo necessário para criação do website; e, de abertura de processo junto ao Núcleo de Inovação Tecnológica (NIT-Ifal) para registro como modalidade de programa de computador no Instituto Nacional de Propriedade Intelectual (INPI).

A Fase 1 - Briefing da ferramenta EdESIGN - consistiu na fase para elaboração da plataforma de interação e organização pedagógica dos dados produzidos pela revisão dos bancos de dados 1 e 2 . Nessa fase foram selecionados os módulos para compor a ferramenta: módulo acadêmico (alunos e professores), módulo empresa e módulo profissional. Os conteúdos dos módulos foram separados com base em cada grupo estabelecido, objetivo e justificativa.

De acordo com Ferreira (2011, p. 751), as informações contidas no briefing funcionam como inputs que permitem que o profissional criativo tenha uma percepção mais apurada sobre o público-alvo e suas demandas. Contém informações sobre objetivo do projeto, público-alvo, necessidades, limitações, entre outros, para que possam ser visualizadas oportunidades que auxiliarão no desenvolvimento das soluções de projeto.

No caso da ferramenta EdESIGN, a elaboração do briefing do projeto foi pensada como forma de auxiliar a equipe na compreensão mais ampla das possibilidades e limitações. Nesse processo, contou-se com o suporte de outra técnica: o brainwriting. Segundo Ramos (2018, online), brainwriting consiste na prática de grupo, em que se realizam registros escritos de ideias com o propósito de se alcançar o objetivo específico. O brainwriting da plataforma EdESIGN foi motivado por 4 questões-guias: 1. Qual o principal objetivo para a ferramenta EdESIGN ter um site? 2. Como é a presença de plataformas similares? 3. O que esperamos da internet para a EdESIGN? 4. Existem processos manuais que podem ser resolvidas com soluções web?

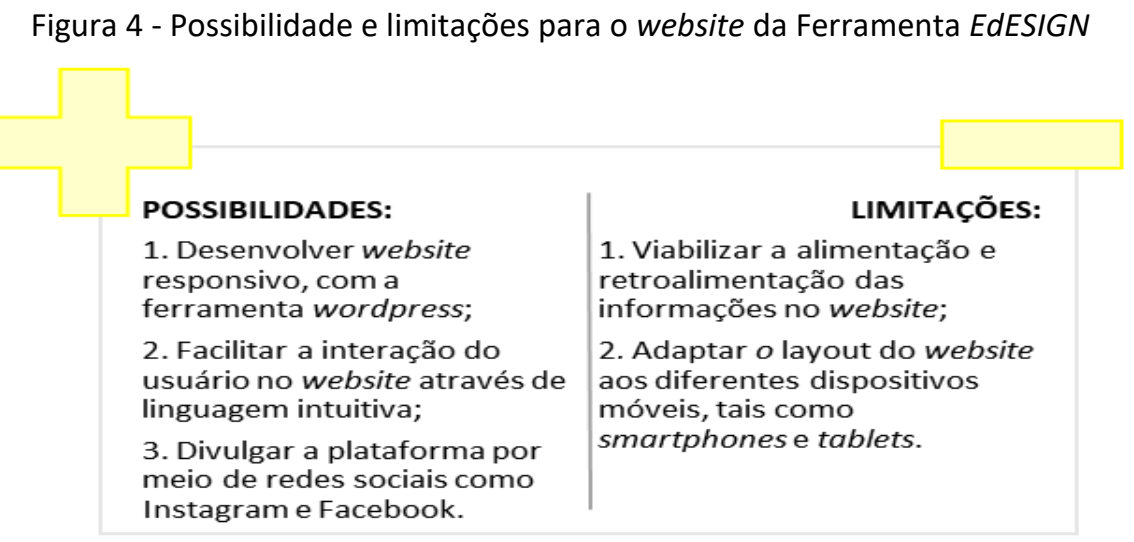

Fonte: Projeto PIBIC 2017-2018 (GEID; GEMPE, 2017)

A partir das ideias e reflexões obtidas na sessão de brainwriting, o briefing do projeto foi elaborado. Nele, foram expostos os principais desafios a serem resolvidos pela equipe. $O$ primeiro desafio avaliado por meio do briefing foi a revisão e refinamento dos saberes e competências dos bancos de dados 1 e 2, considerando que a criação da plataforma tinha por objetivo disponibilizar o material para o público-alvo. O segundo desafio foi o desenvolvimento de website responsivo, utilizando a ferramenta wordpress, considerando que o site para web foi o meio escolhido para disseminar os produtos das pesquisas realizadas (Figura 4). 
A Fase 2 - Elaboração da Ferramenta EdESIGN na forma de site da web - representou a etapa de criação (processo de design) e de configuração do formato web. Foram definidos os esquemas dos módulos (como eles seriam representados, incluindo ícones e imagens) e as informações que estariam em cada seção ou aba do site. A estruturação dos primeiros modelos gráficos para o site pela equipe de pesquisa encontra-se ilustrada na Figura 5.

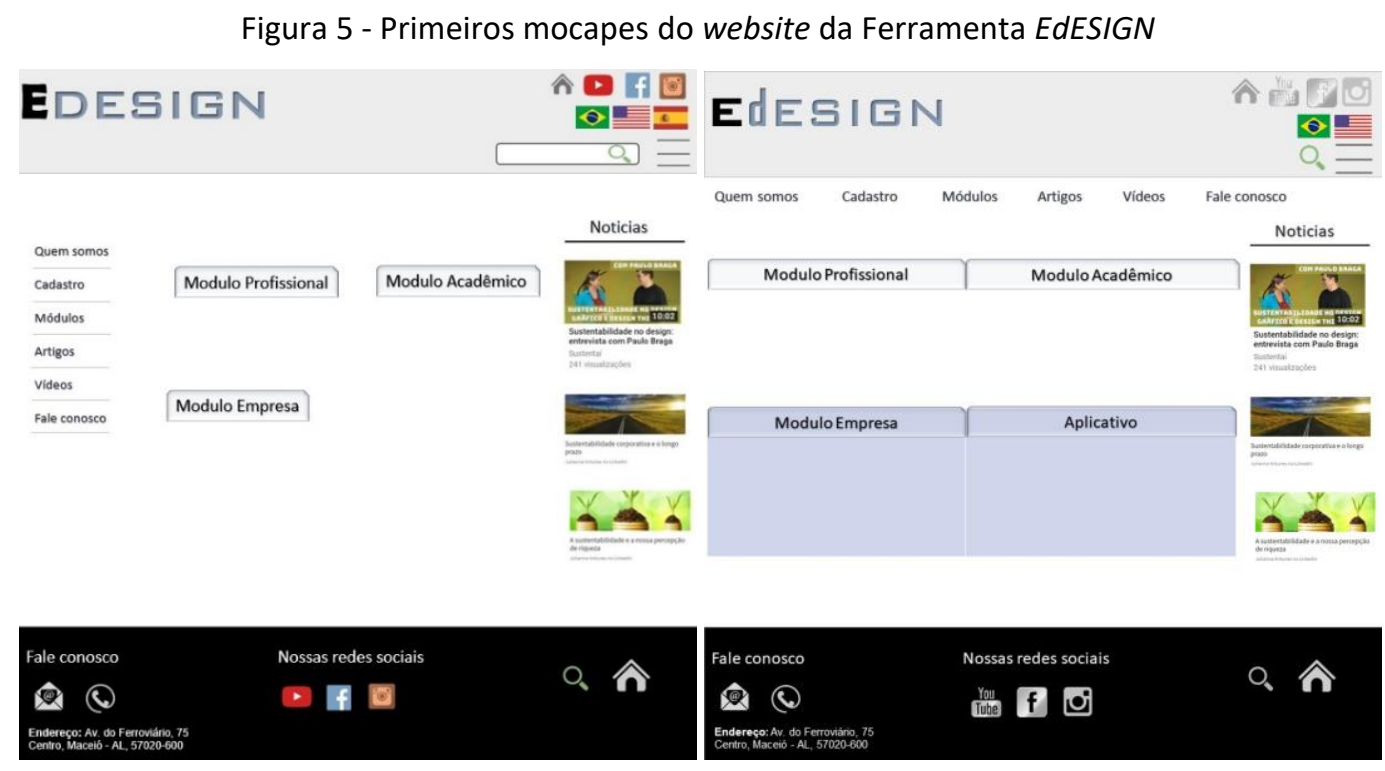

Fonte: Projeto PIBIC 2017-2018 (GEID; GEMPE, 2018)

Durante o desenvolvimento das atividades da Etapa 2, foi pensado de que forma seria criada a plataforma da ferramenta EdESIGN para que o público-alvo pudesse fazer o melhor uso do conteúdo disponibilizado. O objetivo da ferramenta EdESIGN era que a experiência para o visitante pudesse ser agradável em qualquer tipo de dispositivo - smartphones, tablets, notebooks ou computadores de mesa; sobretudo, os smartphones, por serem os mais usuais e estarem sempre à mão do usuário. O resultado esperado pela ferramenta era que o usuário navegasse sem nenhum problema operacional, podendo ter os objetivos de busca alcançados ao acessá-la.

Para que a construção da plataforma EdESIGN fosse criada de modo a atender ao seu público-alvo de forma satisfatória era necessário, primeiramente, construir o perfil desse público a ser atingido por ela. Foi utilizada a pesquisa Survey, elaborada pela equipe de pesquisa na forma de questionário online, contemplando perguntas abertas e fechadas, sendo em sua maioria perguntas de múltipla escolha.

Após a elaboração do questionário a pesquisa foi distribuída no aplicativo WhatsApp aos grupos das turmas e de professores de Design de Interiores do IFAL; nos grupos fechados do Facebook Navegações (DESIGN-IFAL) (298 membros) e DESIGN DE INTERIORES - IFAL (634 membros), também voltado à comunidade do Ifal. Os questionários também foram enviados por WhatsApp e por e-mail para os empresários do ramo moveleiro. Para alunos egressos do CST em Design de Interiores do Ifal, o questionário foi enviado via Direct do Instagram e pelo número pessoal do WhatsApp. O questionário ficou disponível entre os dias 04 e 25 de maio de 2018 para que as pessoas tivessem tempo suficiente para respondê-lo, contendo perguntas simples e objetivas, sendo 14 questões fechadas e 3 abertas para traçar: Perfil Pessoal, Uso da Internet, Hábitos de Leitura, Design e Sustentabilidade e Expectativas.

Os perfis (ou personas) da plataforma foram construídos a partir das respostas coletadas na Survey. As respostas a partir de $50 \%$ foram consideradas como características do grupo. No 
grupo dos alunos foram respondidos 14 questionários; dos professores, 10 questionários; dos profissionais, 16 questionários; e dos empresários, 2 questionários.

De acordo com Vianna et al. (2012, p. 80), "personas são arquétipos, personagens ficcionais, concebidos a partir da síntese de comportamentos observados entre consumidores com perfis extremos. Representam as motivações, desejos, expectativas e necessidades, reunindo características significativas de um grupo mais abrangente". Como resultados obtidos, foram construídas as personas do: aluno, professor, empresário local e profissional de design/egresso.

\section{Resultados e Discussões}

\subsection{Revisão dos bancos de dados}

Na Fase 1 do Estudo de Caso, foi realizada a revisão dos saberes e competências obtidos no Projeto A, em 2016-2017. O Quadro 1 apresenta os resultados da revisão parcial e revisão final quanto aos saberes, competências e conceitos elencados nos contextos formativos no âmbito do CST em Design de Interiores do Ifal.

Quadro 1 - Revisão de Saberes, Competências e Conceitos do Projeto A (PIBIC 2016-2017)

\begin{tabular}{lccc}
\hline Projeto A & Produção 2016-2017 & Revisão Parcial & Revisão Final \\
\hline Saberes & 60 & 32 & 28 \\
Competências & 27 & 25 & 23 \\
Conceitos & 0 & 15 & 11 \\
\hline
\end{tabular}

Fonte: Projeto PIBIC 2017-2018 (GEID; GEMPE, 2018)

Foram revisados 60 saberes e 27 competências, resultantes de 94 fichas, sendo 17 de Pesquisa Bibliográfica, 10 Fichas Documentais e, 67 Fichas Etnográficas. Na revisão parcial do projeto $A$, houve redução considerável na quantidade de saberes, devido à própria ação metodológica do exercício de novo olhar sobre os dados, o que ocasionou o acréscimo de mais uma categoria que não fora apresentada na pesquisa anterior: os conceitos.

Esses conceitos foram integrados à plataforma da EdESIGN no módulo "Dicas", sendo um conteúdo destinado à complementação de informações sobre a temática Sustentabilidade, constituindo-se um resultado novo, obtido dentro do caminhar da pesquisa em 2017-2018.

Para revisão parcial e final do banco de dados 2, foram revisitados os requisitos socioambientais e as diretrizes para o Design de Sistema Ecoeficiente, definidos por Vezzoli (2010), considerados no projeto $B$, como correlatos aos saberes e às competências, aplicados no contexto empresarial, sendo realizada nova reflexão de cada saber e competência para o contexto profissional. Foram revisados 11 saberes, 34 competências e 9 conceitos, resultantes de 15 Fichas de Pesquisa Bibliográfica, 4 Fichas de Pesquisa Documental, 51 Fichas de Pesquisa de Campo e 8 Fichas de Análise. O Quadro 2 apresenta os resultados obtidos na revisão parcial e revisão final.

Quadro 2 - Revisão dos Saberes, Competências e Conceitos do Projeto B (PIBIC 2016-2017)

\begin{tabular}{lccc}
\hline Projeto A & Produção 2016-2017 & Revisão Parcial & Revisão Final \\
\hline Saberes & 11 & 13 & 13 \\
Competências & 34 & 37 & 37 \\
Conceitos & 09 & 09 & 12
\end{tabular}


Após o processo de revisão e (re)classificação, além de aperfeiçoados os saberes e as competências já existentes, o conteúdo foi editado e compilado para atender aos objetivos da pesquisa 2017-2018. Os saberes e as competências revisados dos projetos A e B encontram-se enumerados nas Figuras 6 e 7, respectivamente; e apresentados, a seguir.

Figura 6 - Revisão Final dos saberes, competências e conceitos do Projeto A

Saberes
1. Complexidade
2. Consumo consciente
3. Consequências das ações humanas
4. Redução de impactos
5. Formação de opinião
6. Durabilidade dos produtos
7. Tendências
8. Personalização de projetos
9. Produção sustentável
10. Materiais recicladose sustentáveis
11. Coleta seletiva
12. Preocupação como ciclo de vida do produto
13. Tripé economicamente viável, socialmente
justoe ambientalmente responsável
14. Design universal
15. Proatividade
16. Empreenderismo
17. Identidade projetual
18. Interação com empresase outros integrantes
da cadeia produtiva
19. Estímulo da cultura do "faça você mesmo" ou
atribuição de novo uso aos objetos
20. Conhecimento de materiais ecológicose
sustentáveis
21. Conhecimento do trabalho de designers
22. Conhecimento das possibilidades de uso de
materiais recicláveis
23. Conhecimento das formas de reuso de pneus
em projeto de interiores

Competências

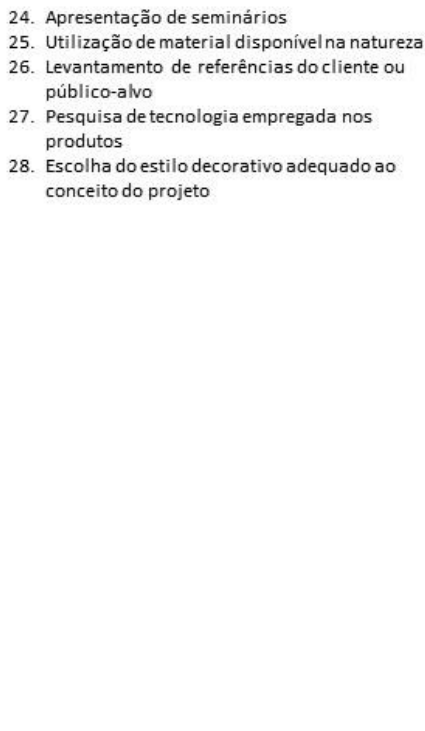

1. Ser e agir de forma sustentável

2. Planejar e projetar ambientes

3. Geras ideias criativas

4. Aplicar os 5 Rs da Sustentabilidade

5. Aperfeiçoar conhecimentos

5. Aperfeiçoar conhecimentos

6. Conhecer os tipos de materiais verdes
7. Criar novas experiências parao consumidor

8. Indicar, especificar produtos

. Desenvolver projetos de paisagismo de interiores

10. Conhecer tendências do mercado

11. Compreender os novos hábitos de consumo

12. Pesquisar empresas fornecedoras de produtos sustentáveis

13. Subverter, adaptar ou dar novo uso/função para produtos

14. Repensar, reprojetar ou reformular

15. Realizar análise espacial do ambiente

15. Realizar analise espacial do ambiente

tema, problema, fenômeno

17. Pensar criticamente frente às questões da

realidade

18. Especificar materiais de acordo com o perfil do

cliente ou público do projeto

19. Prototipar produtos

20. Conhecer materiais de origem animal

21. Conhecer composição de produtos

22. Mobilizar e articular conhecimentos

23. Dominar vocabulário técnico

Fonte: Projeto PIBIC 2017-2018 (GEID; GEMPE, 2018)

Ao longo da revisão de conteúdo e elaboração do site, houve a definição pela equipe de pesquisa de quais saberes, competências e conceitos comporiam cada um dos três módulos - EdA, EdP e EdE - associando-os aos respectivos grupos de interesse.

Figura 7 - Revisão final dos saberes, competências e conceitos do Projeto B

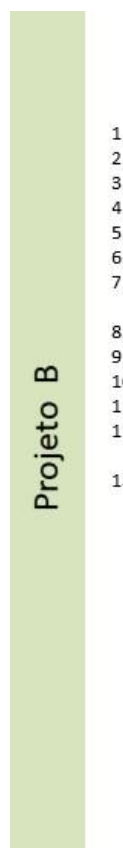

Saberes

Redução dos recursos

Minimização dos resíduos

Valorização dos resíduos

Aplicação do design para recuperaçãoe reuso

Redução da toxidade

Aplicação do design para conservação de ener

Aplicação do design para redução de riscos

crônicos

Melhoria da condições de emprego e trabalho

Fortalecida condiçosdeemprego et

10. Valorização dos recursos locais

1. Aplicação do design para desmontagem

12. Aplicação de design para a minimização de

resíduos

3. Aplicação de design para conservação de

materiais
Competências

\begin{tabular}{|c|c|}
\hline $\begin{array}{l}\text { 1. Reduzir o uso de energia na produção } \\
\text { 2. Ofertar serviço e manutenção }\end{array}$ & $\begin{array}{l}\text { 18. Promover e aumentar a satisfação, motivaçãoe } \\
\text { participação dos empregados }\end{array}$ \\
\hline $\begin{array}{l}\text { 3. Otimizar os recursos integrando na oferta, produto } \\
\text { e serviços do design adequado ao contexto de uso }\end{array}$ & $\begin{array}{l}\text { 19. Promover a satisfação (clientes - empregos - } \\
\text { parceiros) }\end{array}$ \\
\hline 4. Reduzir o uso de energia na distribuição & 20. Aumentar a participação dos empregados \\
\hline 5. Usar formas renováveis de energia & 21. Respeitar e fortalecer as caracteristicas locais \\
\hline 6. Integrar serviços de coleta para a reciclagem à & 22. Promover parcerias com empresas locais \\
\hline oferta do sistema produto & 23. Criar parcerias com iniciativas loca is \\
\hline $\begin{array}{l}\text { 7. Promover alianças-parcerias locaisvisando a } \\
\text { reciclagem em cascata para subprodutos }\end{array}$ & $\begin{array}{l}\text { 24. Facilitar o acesso aos componentes } \\
\text { 25. Simplificar as interfaces dos componentes }\end{array}$ \\
\hline 8. Empregar o design para recuperação de material & 26. Usar o design para simplicidade de montagem e \\
\hline $\begin{array}{l}\text { 9. Empregar o design para recuperação de } \\
\text { componentes }\end{array}$ & $\begin{array}{l}\text { desmontagem } \\
\text { 27. Usar o design para redução da fonte }\end{array}$ \\
\hline 10. Reduzir substâncias tóxicas e perigosas & 28. Usar o design para reciclagem \\
\hline 11. Usar produtos biodegradáveis & 29. Promover a não contaminação, facilitando a \\
\hline 12. Planejar a destinação dos subprodutos/resíduos & compostagem \\
\hline $\begin{array}{l}\text { 13. Estabelecer parcerias com outras empresas- } \\
\text { visando a redução, reutilização e reciclagem de } \\
\text { substâncias tóxicas ou nocivas }\end{array}$ & $\begin{array}{l}\text { 30. Empregar o design para recuperação e reuso de } \\
\text { subprodutos/resíduos } \\
\text { 31. Empregar o design para a incineração de }\end{array}$ \\
\hline $\begin{array}{l}\text { 14. Promover e aumentar a proteção das condições } \\
\text { de trabalho }\end{array}$ & $\begin{array}{l}\text { subprodutos/resíduos } \\
32 \text {. Especificar materiais reciclados }\end{array}$ \\
\hline 15. Promover e aumentar a salubridade e segurança & 33. Especificar materia is recicláveis \\
\hline 16. Promover jornadas de trabalho adequadas & 34. Utilizar o design para longevidade do produto \\
\hline 17. Promover a remuneração justa & $\begin{array}{l}\text { 35. Utilizar o design para a reciclagem contínua } \\
\text { 36. Utilizar o design para a recuperação da } \\
\text { embalagem }\end{array}$ \\
\hline & 37. Fomentar diferentes gostos e estéticas \\
\hline
\end{tabular}

Fonte: Projeto PIBIC 2017-2018 (GEID; GEMPE, 2018) 


\subsection{Elaboração do site: Ferramenta EdESIGN}

Como o atributo principal da ferramenta seria tornar público o conteúdo das pesquisas anteriores, uma das etapas mais relevantes foi a de configuração dos módulos. Nesta etapa foram avaliadas quais as necessidades de cada público-alvo para alinhar qual seria a forma de disponibilizar o conteúdo dos projetos $\mathrm{A}$ e $\mathrm{B}$ de forma objetiva para públicos distintos.

Tendo em vista as diferentes necessidades de cada um dos públicos, definiu-se que designers profissionais e empresários locais teriam conteúdo disponibilizado em ambientes separados. Já alunos e professores seriam agrupados em mesma categoria devido a semelhança de interesses. Assim, a ideia de módulos solidificou-se como forma prática de disponibilizar os conteúdos, direcionados para cada público.

A criação do Módulo Acadêmico (EdA) promove a geração de conhecimentos e inovações em Design e Sustentabilidade, tanto do ponto de vista da metodologia de Design, com ênfase no Design para o Meio Ambiente, quanto do ponto de vista do projeto de Design junto aos alunos e professores do CST em Design de Interiores do IFAL e outras IES, visando a integração das boas práticas entre IES e setores produtivos.

Por conseguinte, o Módulo Profissional (EdP) permite a articulação dos saberes em Design e Sustentabilidade entre os processos criativos dos designers de interiores e os processos técnicos e as boas práticas das empresas locais, através de inovações que gerem competitividade e renda, além da melhoria do desempenho produtivo e socioambiental de bens e serviços.

Já o Módulo Empresa (EdE) gera oportunidades no tocante ao Design e à Sustentabilidade, por meio de parcerias com empresas locais de Maceió e entorno, para a melhoria do desenvolvimento de projetos, produtos, serviços, processos e/ou sistemas da produção local.

Por último, o Módulo Dicas cria ambiente interativo da plataforma EdESIGN, dentro do site da web, intermediado pelos mascotes da plataforma. Na figura 8, visualiza-se a definição final dos ícones que representam os módulos descritos e os respectivos objetivos.

Figura 8 - Ícones e Objetivos dos Módulos da Ferramenta

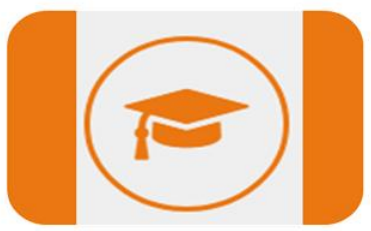

\section{Módulo 1: Acadêmico}

- Promover a geração de conhecimentose

inovações em Design e

Sustentabilidade, tanto do ponto de vista da

metodologia de Design

com ênfase no Design

para o Meio Ambiente

quanto do ponto de vista

do projeto de Design junto

aos alunos e professores

do CST em Design de

Interiores do IFAL e outras

IES (integração das

práticas entre IES e setores produtivos)

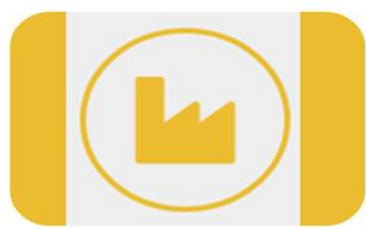

Módulo 2: Empresa

- Gerar oportunidades no tocante ao Design e à Sustentabilidade, por meio de parcerias com empresas locais de Maceió e Entorno, para a melhoria do

desenvolvimento de

produtos, serviços e/ou

processos da produção

local.

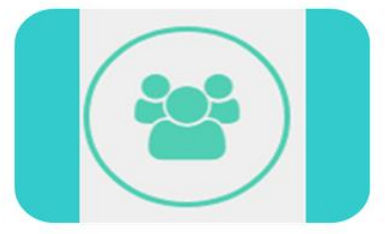

Módulo 3: Profissional

- Permitir a articulação dos saberes em Design e

Sustentabilidade entre os

processos criativos dos

designers de interiores e os

processos técnicos e boas

práticas das empresas

locais, através de

inovações que gerem

competitividade e renda

além da melhoria do

desempenho produtivoe

socioambiental de bens

serviços.

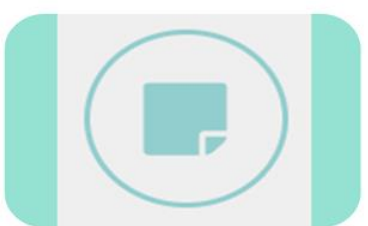

Módulo 4: Dicas|Mascotes

- Criar o ambiente interativo da plataforma EdESIGN. dentro do website.

intermediado pelos

mascotes da plataforma. 
A Figura 9 exibe como a página inicial da plataforma EdESIGN apresenta-se para os usuários. É possível notar o design minimalista e os elementos da estrutura do site como: quem somos, fale conosco, módulos, publicações, entre outros.

Figura 9 - Página principal da ferramenta (Home, parte 1)

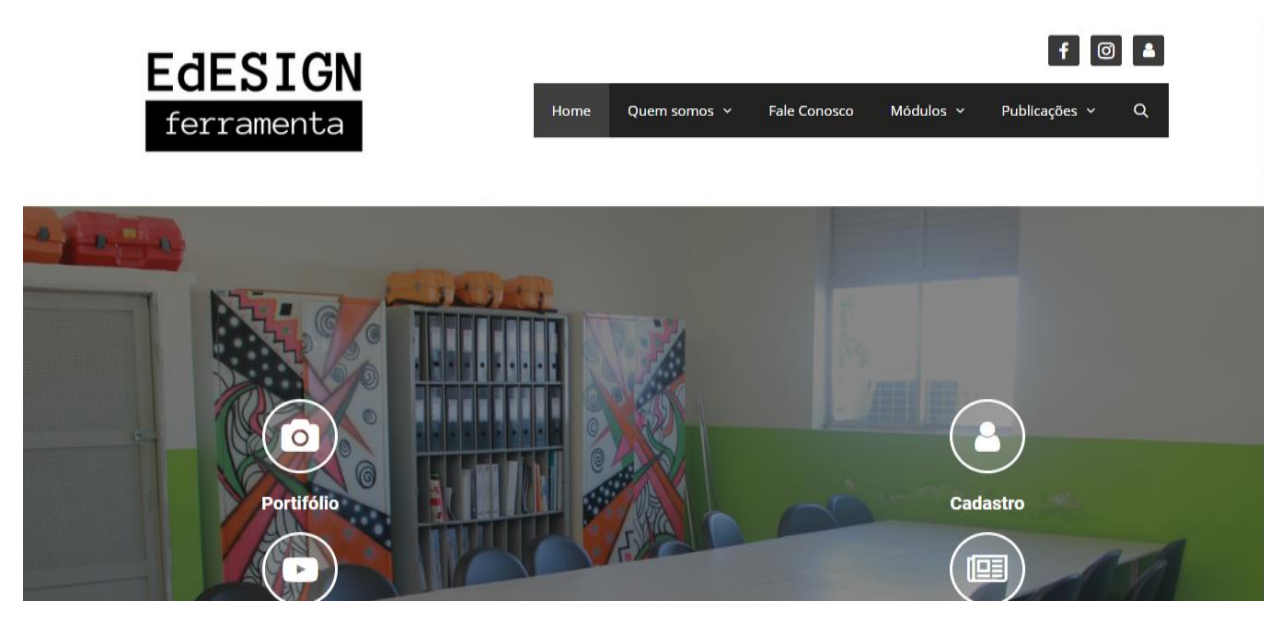

Fonte: Projeto PIBIC 2017-2018 (GEID; GEMPE, 2018)

Para acessar o conteúdo dos módulos é necessário fazer o cadastro inicial, criando login e senha para acessos futuros. O conteúdo de cada módulo destina-se ao público específico. Estudantes e professores terão acesso apenas ao módulo EdA, os profissionais poderão acessar o módulo EdP e os empresários do ramo moveleiro encontrarão conteúdo voltado para a sua prática profissional no módulo EdE. Todos acessam o módulo Dicas, guiado pelos mascotes.

Na Figura 10, é possível visualizar a continuação da home page, com a apresentação sobre o que é a plataforma, além da visualização de dois módulos da ferramenta.

Figura 10 - Página principal da ferramenta (Home, parte 2)

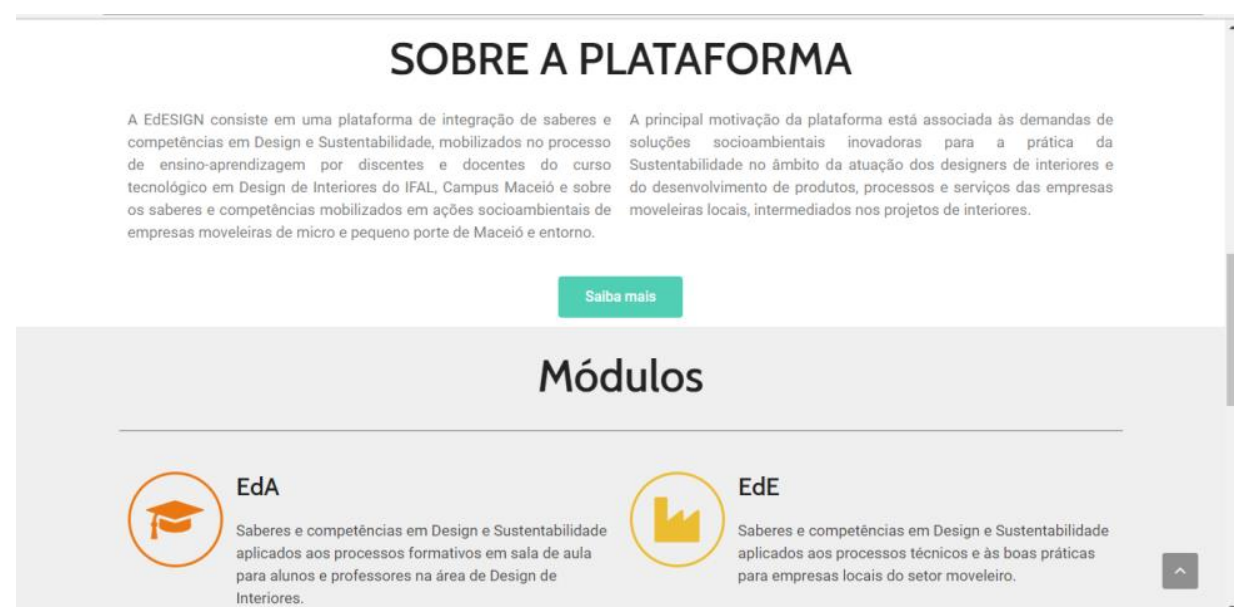

Fonte: Projeto PIBIC 2017-2018 (GEID; GEMPE, 2018)

Ressalta-se que as figuras 9, 10 e 11 desta seção são um preview de algumas das seções da Ferramenta EdESIGN com o intuito de demonstrar o design de interface do usuário. Assim que a ferramenta for lançada, os usuários terão acesso tanto às seções abertas a todos os públicos, como às específicas. 
A Figura 11, a seguir, mostra o conteúdo da seção "Quem Somos". Nela é possível ter acesso às informações complementares que não aparecem na breve apresentação da Home Page.

Figura 11 - Página Sobre a Plataforma de acesso ao Saiba mais

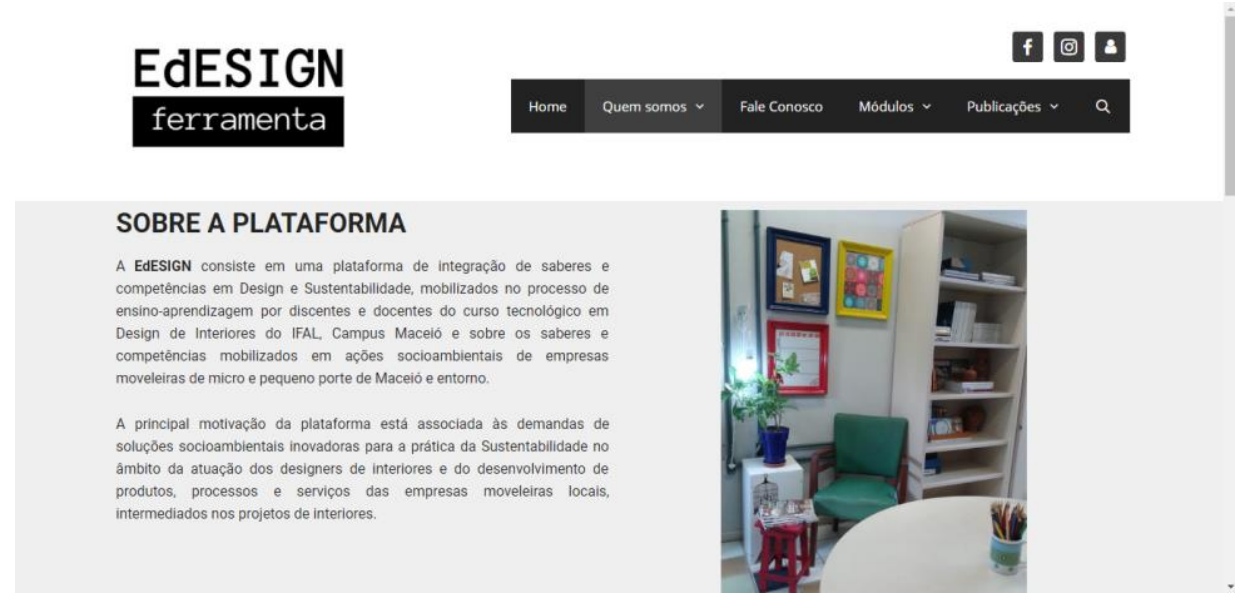

Fonte: Projeto PIBIC 2017-2018 (GEID; GEMPE, 2018)

Para ampliar os canais de comunicação com o público, a Ferramenta EdESIGN também terá perfis em redes sociais como Facebook e Instagram. Dessa forma, espera-se ampliar o alcance da plataforma, ultrapassando o âmbito local e contribuindo para disseminação dos conhecimentos gerados para todos os interessados em aprender mais sobre a inter-relação entre Design e Sustentabilidade, intermediada pelo Design de Interiores e Design de Móveis.

\section{Considerações Finais}

A criação da ferramenta EdESIGN na forma de site da web estabelece novo marco de estudos e pesquisas para os grupos de pesquisa envolvidos: GEID-NPDesign e GEMPE, ambos do Ifal Campus Maceió; e, abre novo ciclo de estudos aplicados, voltados à extensão tecnológica junto aos grupos específicos do público-alvo da ferramenta, inclusive a execução dos passos da Fase 3 , a partir de situações reais de trabalho entre designers de interiores e empresas locais para integração de saberes, competências e conceitos inter-relacionados ao Design e à Sustentabilidade.

Construída de forma multi e interdisciplinar, a ferramenta EdESIGN envolveu a aquisição de novos conhecimentos pela equipe de pesquisa, com a geração de expertise que contribuirá para novas práticas docentes em contextos formativos junto ao Curso Tecnológico em Design de Interiores, bem como para novas pesquisas científicas, por meio da prática de pesquisa aplicada ao desenvolvimento de Tecnologias Educacionais integradas às Tecnologias Ambientais, interrelacionadas ao Design e à Sustentabilidade. O trabalho colaborativo na forma de coworking acadêmico foi valorizado em todas as etapas dessa aprendizagem.

\section{Agradecimentos}

Ao Conselho Nacional de Desenvolvimento Científico e Tecnológico (CNPq) e ao Programa Institucional de Bolsas de Iniciação Científica (PIBIC) do Ifal, pelo fomento à pesquisa no período de agosto de 2017 a julho de 2018, por meio da concessão de bolsas de pesquisa; e, a toda equipe de pesquisa que, além de duas bolsistas PIBIC-CNPq-Ifal, foi composta por duas alunas voluntárias 
- Camila Felix da Silva e Marina do Nascimento Gonçalves - e por uma aluna estagiária Cláudia Vanessa da Silva, do CST em Design de Interiores do Ifal.

\section{Referências}

BRASIL. Lei no 13.369, de 12 de dezembro de 2016. Dispõe sobre a garantia do exercício da profissão de designer de interiores e ambientes e dá outras providências. Disponível em www.planalto.gov.br. Acesso em 27 março 2019.

COSTA, M. A; COSTA, M. Projeto de pesquisa - entenda e faça. 6. Ed. - Petrópolis, RJ: Vozes, 2014.

FERREIRA, A. R. A estratégia no processo de criação em publicidade e propaganda. Revista Estudos. Goiânia, v. 38, n. 4, p. 749-754. 2011.

LIBÂNEO, J. C. A organização e a gestão da escola: teoria e prática. 5. ed. Rio de Janeiro: Alternativa, 2004.

OLIVEIRA SANTOS, A. P. Q. R. S; RAPÔSO, A. L. Q. R. S.; FARTES, V. Ecopráticas na EPT: desenvolvimento, meio ambiente e sustentabilidade. Maceió: IFAL, 2011.

PLATCHECK, E. R. Design industrial: metodologia de EcoDesign para o desenvolvimento de produtos sustentáveis. São Paulo: Atlas, 2012.

RAMOS, R. Brainwriting. Disponível em: <https://www.infoescola.com/administracao_/brainwriting/>. Acesso em: 29 ago 2018.

SAMPAIO, C. P. de [et al.]. Design para a sustentabilidade: dimensão ambiental. Curitiba, PR: Insight, 2018.

THOMPSON, R. Materiais sustentáveis, processos e produção. Trad. Débora Isidoro. São Paulo: Editora Senac, 2015.

VEZZOLI, C. Design de sistemas para sustentabilidade: teoria, métodos e ferramentas para o design sustentável de sistema de satisfação. Salvador: EDUFBA, 2010.

VIANNA, M.; et al. Design thinking: inovação em negócios. Rio de Janeiro: MJV Press, 2012. 